\title{
A simplified model of pathogenic pollution for managing beaches
}

\author{
Derek Stretch* and David Mardon \\ Centre for Research in Environmental, Coastal \& Hydrological Engineering (CRECHE), University of KwaZulu-Natal,
}

Durban 4041, South Africa

\begin{abstract}
Existing models for urban runoff water quality and dispersion in the coastal zone are cumbersome for application to everyday management of beach use. A simplified model is therefore proposed and tested using a case study. The model captures the key physical processes involved in mixing and dispersion of pathogenic pollution at beaches, and should therefore have some generality. Simulations using the model are shown to adequately reproduce measurements at the case study site. The utility of the model is demonstrated by analysing a specific case of poor water quality at one of the beaches and by using it to estimate the reduction in pollution loadings needed to meet water quality guidelines.
\end{abstract}

Keywords: beach-water quality model, pathogenic pollution, storm-water runoff, E. coli

\section{Introduction}

Pollution of coastal waters can have negative impacts on public health and the tourism industry. Water-borne pathogens (i.e. disease-causing organisms) can be transmitted when people come into contact with polluted water. Sources of pathogenic pollution at beaches include sewer outfalls, storm-water drains and rivers. Studies by Wright et al. (1993) and Mardon and Stretch (2004) have highlighted how such pollution can render beaches in the Western Cape and KwaZulu-Natal unsuitable for recreational use.

Monitoring beaches for pathogenic pollution typically involves testing for the presence of indicator organisms such as Escherichia coli (E. coli) and/or Enterococcus. Water quality guidelines (e.g. US EPA, 1986; COM, 2002; DWAF, 1995) specify limits, based on epidemiological studies, for indicator concentrations. Weekly or fortnightly water sampling is usually required to implement these guidelines. Mardon (2003) found that there was no significant correlation between successive fortnightly samples at a case study site (Durban, South Africa) indicating that the timescale for changes in pathogenic pollution in the near-shore zone was much shorter than the sampling interval. Therefore high levels of pollution may occur undetected between sampling times. However, more frequent sampling is costly and microbiological analysis of the samples takes $24 \mathrm{~h}$ to $48 \mathrm{~h}$ to complete anyway (Standard Methods, 1992). Therefore a model to predict pathogen levels at beaches between sampling is required to effectively manage exposure risks. Models are also useful for addressing "what-if" scenarios concerning future changes.

US EPA (1999) reviewed the application of water quality models to beaches. The review discusses urban runoff quality models (e.g. SWMM, HSPF), as well as models of dispersion and mixing in receiving water-bodies (e.g. SMTM, QUAL2E, CORMIX). These models are not generally well suited for application in the

* To whom all correspondence should be addressed.

面+2731 260-1064; fax:+2731 260-1411

e-mail: stretchd@ukzn.ac.za

Received 12 August 2004; accepted in revised form 27 October 2004.
South African context due to a lack of detailed data for set-up and calibration, particularly for the more complex models. Coleman and Simpson (1996) adapted aspects of the HSPF and SWMM models for urban runoff quality predictions in South African catchments. However, this type of model, intended for aiding storm-water management and design, is too detailed and unwieldy for beach pollution. The aim of the present study was therefore to investigate and develop a simplified model that does not require extensive input information, but can adequately predict beach pollution for management purposes.

\section{Model formulation}

From a modelling perspective, pollution dispersion in the nearshore coastal environment involves complex processes such as wind-generated surface advection, wave-driven long-shore currents, cross-shore mixing processes due to wave and tidal forcing, and localised effects such as rip currents. Both mixing and natural decay processes reduce pollution within the nearshore zone: e.g. light, through photo-oxidation, can be a major factor in bacterial population changes (Chamberlin and Mitchell, 1978). The model described herein greatly simplifies these processes but is not a pure "blackbox" approach-a connection to the main underlying physical processes is maintained in the hope of achieving some generality and to help with parameter estimation. The model is formulated in statespace form. E.coli concentrations were used as state variables for the case study reported here, but other water quality indicators can probably be used, subject to appropriate testing and calibration.

A more detailed discussion of aspects concerning the model formulation and development, particularly the representation of the underlying physical processes and model estimation procedures, is given in Mardon (2003).

\section{The model structure}

The beach zone is modelled as a series of cells (see Fig. 1) with specified physical characteristics, i.e. length, volume and orientation. The size of the cells determines the extent of spatial averaging in the model since each cell is assumed to be homogeneous with 


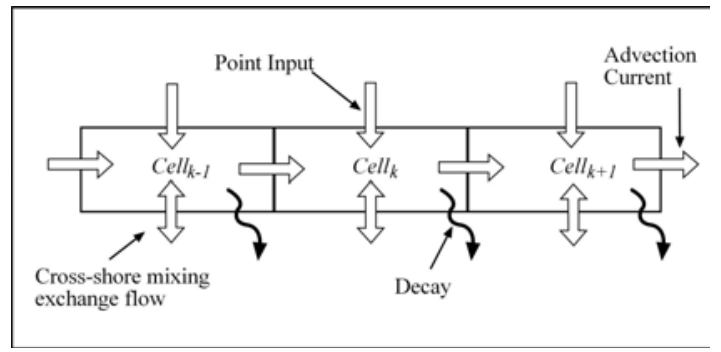

Figure 1

Schematic depicting the structure of the model and the coastal processes involved

uniform pollution concentration.

Cells may have point source pollution inputs, e.g. from stormwater drains. The evolution of the pollution concentrations incorporating the processes depicted in Fig. 1, is governed by a species conservation equation with the symbolic form:

$$
\frac{d c_{k}}{d t}=-(\text { Decay }+ \text { Mixing }) \pm \text { Advection }+ \text { Inputs }
$$

where:

$c_{k}$ is the concentration in the $k^{\text {th }}$ cell.

Decay and mixing processes are modelled as simple linear first-order processes, namely:

$$
\left.\frac{d c_{k}}{d t}\right|_{\text {Decay \& Mixing }}=-c_{k}\left(\frac{1}{T_{d}}+\frac{1}{T_{M}}\right)
$$

where:

$T_{d}$ is a decay timescale for the indicator micro-organisms

$T_{M}$ is a mixing timescale.

Chamberlin and Mitchell (1978) and US EPA (1985) reviewed the decay of coliform bacteria in natural water-bodies and gave a median value of $T_{d} \sim 1$-day. The timescale $T_{M}$ represents the time to replace the cell volume by cross-shore exchange flow and mixing. It will depend on the physical characteristics of the cells and environmental forcing from wind, waves, and tides. Values of the order of 1-day seem reasonable in the context envisaged here. From a modelling perspective, the effects of mixing and decay are indistinguishable, and they are lumped together as a single dissipative process with timescale $T_{D}$ defined by the harmonic combination $1 / T_{D}=\left(1 / T_{d}+\right.$ $\left.1 / T_{M}\right)$.

Advection currents can move pollution from one cell to another (see Fig. 1). Species conservation implies:

$$
\left.\frac{d c_{k}}{d t}\right|_{\text {Advection }}=-\frac{\left(c_{k}-c_{k \pm 1}\right)}{T_{A}}
$$

where:

$T_{A}$ is an advection timescale and represents the time for fluid particles to cross the cells i.e. $\mathrm{T}_{\mathrm{A}}=\mathrm{L}_{\text {cell }} / \mathrm{U}_{\mathrm{A}}$ if $\mathrm{L}_{\text {cell }}$ is the cell length and $U_{A}$ the long-shore current speed depicted in Fig. 1. The advection direction determines the sign of the second cell index in $\mathrm{Eq}(3)$.

Advection is controlled by factors such as wave-driven alongshore currents and wind-driven surface currents. In the case of freshwater surface plumes, it seems likely that wind-driven effects would dominate. Mardon and Stretch (2002) showed that measured surface currents (up to $2 \mathrm{~m}$ depth) respond rapidly to local winds and that the speed of the currents can be correlated with the wind speed. (see also Wu, 1974; Chao, 1988; Cheng and Mitsuyasu, 1992). Typically we expect $T_{A}$ to be of the order of 1-day, depending on prevailing wind conditions and cell sizes.

Pollution is assumed to enter the cells by point inputs $i_{k}(k=1$, $2,3, .$.$) some of which may be zero. These inputs are associated with$ rainfall runoff from their associated catchments. Allowance can also be made for dry period flows where appropriate. The pollution loadings of the inputs are key driving factors for beach-water quality and are discussed in the next section.

Combining the decay, mixing, and advection from Eqs. (1) to (3) yields a basic model equation for each cell:

$$
\frac{d c_{k}}{d t}=-c_{k}\left(\frac{1}{T_{D}}+\frac{1}{T_{A}}\right)+\frac{c_{k \pm 1}}{T_{A}}+i_{k}
$$

Note that in principle the parameters $T_{D}$ and $T_{A}$ can be different for each cell, and can be time-varying. However, for small model domains, it may be appropriate to consider them to be the same for all the cells.

The model can be written in state-space form as a linear dynamic system, namely:

where:

$$
\mathrm{d} \boldsymbol{C}(t) / \mathrm{d} t=\boldsymbol{A}(t) \cdot \boldsymbol{C}(t)+\mathbf{I}(t)
$$

$\boldsymbol{C}(t)$ is a vector of cell concentrations (the state vector)

$\boldsymbol{A}(t)$ is a coefficients matrix comprising the time scales $T_{D}, T_{A}$. $\mathbf{I}(t)$ is a vector of cell inputs.

Note that a reversal in advection direction simply transposes the coefficient matrix $\boldsymbol{A}(t)$.

Model predictions are usually required at regular time intervals. A discrete-time version of the model Eq. (5) can be derived for a sequence $\{\boldsymbol{C}(m), m=0,1,2, \ldots\}$ at time intervals $\Delta t$ apart. Whence:

where:

$$
\boldsymbol{C}(m+1)=\boldsymbol{\Phi}(m, m+1) \cdot \boldsymbol{C}(m)+\mathbf{I}(m+1)
$$

$\mathbf{I}(m+1)$ is a vector of time-integrated pollution inputs (discussed below)

$\boldsymbol{\Phi}(m, m+1)$ is a state transition matrix - if $\boldsymbol{A}(t)$ is assumed constant for the interval $(t, t+\Delta t)$, it is given by (e.g. Chen, 1970)

$$
\boldsymbol{\Phi}(m, m+1)=\exp (\boldsymbol{A} . \Delta t)
$$

\section{Modelling the pollution inputs}

The pollution concentrations in urban runoff are a function of landuse, and may vary with the intensity and duration of rainfall events. Higher concentrations typically occur near the beginning of rainfall events, a phenomenon known as the "first-flush" (e.g. Hager, 2001). The "first-flush" is related to a build-up of pollutants during dry periods between rainfall events. A simple "half-inch rule" has been widely used in storm-water management where it is assumed that $90 \%$ of pollution loadings are transported by the first half-inch of runoff, although the accuracy of this rule is questionable (Chang et al., 1990). Existing models that can predict pollution loadings for urban runoff (e.g. SWMM) incorporate this process in various ways. However, the details of build-up and wash-off of pollutants are of little direct relevance to predicting beach-water quality. For the present model a simple version of the "rating-curve" approach (Heaney et al., 1975) has been adopted where input loadings are based on "event mean concentrations" (i.e. flow-weighted average concentrations).

The volume of runoff input $Q$ to each cell during an interval $(m$, $m+1$ ) is calculated using the well-known rational formula (e.g. Chow et al., 1988), namely: 
$Q=\alpha \cdot R \cdot A_{c}$

where:

$R$ is the rainfall depth

$A$ is the catchment area

$\alpha$ is a runoff coefficient.

Each catchment is assumed to have a characteristic "event mean concentration" $C_{E M C}$ linked to its runoff, yielding a pollution loading Q. $C_{E M C}$ for each event. If appropriate, additional pollution loadings due to dry-period flows can also be added to the inputs from each catchment.

A further simplification is introduced by assuming that inputs occur as a lumped pulse at the end of each interval and that they mix instantaneously with the receiving cell volume. The cell states are therefore updated in two stages at each time step: firstly a zero input response is calculated from Eq. (6) as:

$$
\boldsymbol{C}^{(0)}(m+1)=\boldsymbol{\Phi}(m, m+1) \cdot \boldsymbol{C}(m)
$$

The mixing of the inputs into each cell, assumed to conserve the total volume, then implies that:

where:

$$
c_{k}(m+1)=\left(V_{\text {cell }} \cdot c_{k}^{(0)}(m+1)+\mathrm{Q} \cdot C_{E M C}\right) /\left(\mathrm{Q}+V_{\text {cell }}\right)
$$

$V_{\text {cell }}$ is the $k^{\text {th }}$ cell volume

Q. $C_{E M C}$ is the pollution loading for the $k^{\text {th }}$ cell and for time interval $(m, m+1)$.

\section{Model implementation}

The simplicity of the model makes it possible for it to be implemented entirely on a personal computer using standard spreadsheet software. A short custom-written macro is used to solve the system equations at each time step. A one-year simulation using a 10-cell model and 1-day time step can be computed within a few seconds. This affords an interactive environment that has considerable benefits. For example, the effects of an increase or decrease in pollution loadings can be explored instantly. Similarly the contribution of specific pollution sources can be clarified by simply "turning them off” and re-running a simulation, etc. The graphical output capabilities of spreadsheet software may also be used to visualize results interactively.

\section{Model estimation}

The model for pollution mixing and transport is specified by the cell sizes/volumes, decay timescales $T_{D}$, and advection timescales $T_{A}$. These parameters would typically be assumed uniform over the model domain. As noted previously, reasonable estimates of $T_{D}$ and $T_{A}$ may be made from an understanding of the physical processes they represent. The timescale $T_{A}$ can be related directly to actual wind speeds.

Pollution inputs are parameterised by catchment areas $\left(A_{c}\right)$, rainfall-runoff coefficients $(\alpha)$, pollution concentrations $C_{E M C}$, and dry period flows. Parameters such as catchment areas, runoff coefficients and dry-period flow volumes can usually be measured or inferred directly from available physical data. Pollution concentrations $C_{E M C}$, are likely to be very site-specific and accurate estimations of these values will therefore usually require field measurements.

From an estimation and/or calibration perspective there are basically only two "adjustable" parameters for the model, namely the two timescales $T_{D}$ and $T_{A}$ that, as noted previously, are expected

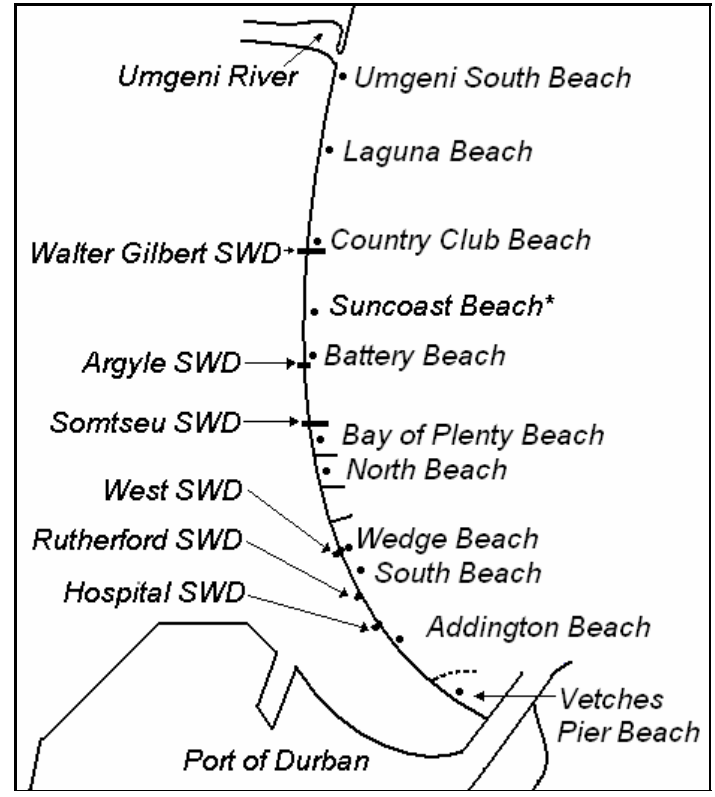

Figure 2

Durban bathing beaches, urban stormwater drains and Umgeni River (* Suncoast Beach not sampled)

to have similar magnitudes. The small number of parameters simplifies the task of estimating "optimal” values.

As noted previously, water quality monitoring is typically done at weekly or longer intervals. This is far too long to resolve the temporal variations due to decay, mixing and dispersion processes. In practice, this means that attempts to estimate the model parameters by matching predicted and measured concentrations at the discrete sampling times is not practical. In this case a statistical estimation procedure is more appropriate where model parameters are calibrated to match selected statistics of the measured time series. Mardon (2003) investigated the model estimation problem in some depth and recommended a statistical estimation procedure based on Monte Carlo simulation methods. The objective function used to define optimal parameter estimates was based on matching a set of statistical metrics that are used in water quality guidelines, such as exceedance statistics (e.g. DWAF, 1995). Also reported were tests of state and parameter estimation using Kalman filtering techniques (e.g. Jazwinski, 1970). This approach requires extending the system equation (5) to incorporate uncertainties in observations, inputs and system parameters, thereby defining a stochastic dynamic system The method was shown to work when accurate data for the inputs are available, but this is seldom the case in practice.

A Maximum Likelihood approach (e.g. Edwards, 1984) may also be used for parameter estimation. A log-normal probabilistic model for beach pollution concentrations is usually appropriate as verified by Mardon (2003) for beaches in Durban.

\section{Case study: Application to Durban beaches}

Durban is situated on the east coast of South Africa and has a subtropical climate with annual rainfall of $1000 \mathrm{~mm}$. A $7.5 \mathrm{~km}$ section of coastline, extending from the port entrance in the south to the Umgeni River in the north (see Fig. 2) was used to test the simplified model proposed here. The coastline is roughly aligned with prevailing wind directions at this location. A local government agency samples the water quality of ten beaches fortnightly while six urban storm-water drains (labelled SWD in Fig. 2) and the Umgeni 


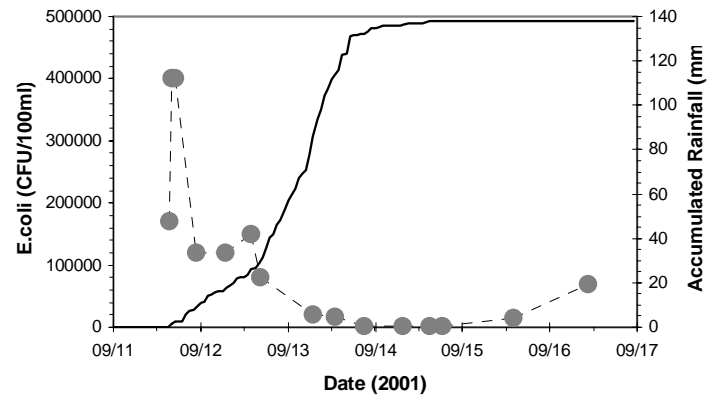

- - - - Argyle SWD E.coli (CFU/100ml) — Accumulated Rainfall (mm)

Figure 3

Argyle SWD E.coli concentrations and accumulated rainfall during a single storm event

River are sampled at approximately monthly intervals. A 4-year archive of E. coli data from 1999 to 2002 was used for model testing. Daily rainfall and average wind speed/direction were obtained for the same period from the South African Weather Service.

Mardon and Stretch (2004) reviewed the water quality of the beaches in this area. It was shown that the beaches from Vetches to Bay of Plenty generally have low pathogenic pollution levels. However, the beaches from Battery Beach northwards often fail South African and International Water Quality Guideline limits.

\section{Field surveys}

To supplement the available information, two brief field surveys were carried out to investigate the pollution wash-off process and to obtain preliminary estimates of the timescales $T_{D}$ and $T_{A}$. The surveys focused only on the Argyle storm-water drain and the Battery Beach area.

During the first field survey, flows and water quality were recorded for the Argyle SWD during a single rainstorm event. E. coli concentrations are shown plotted together with accumulated rainfall in Fig. 3. The rainfall was recorded at a weather station situated 16 km from the Argyle SWD catchment. A typical "first-flush" effect is evident in Fig. 3 - runoff pollution concentrations peaked at high values near the start of the rainfall and then reduced approximately exponentially with increasing rainfall. There is a smaller secondary peak associated with an increase in rainfall intensity. The event mean concentration was estimated from the data as $40000 \mathrm{CFU} / 100 \mathrm{~m} \ell$. The initial peak was at least ten times higher than this: it was in fact at the upper detection limit for the testing procedure used (400 000 $\mathrm{CFU} / 100 \mathrm{~m} \ell$ ). For comparison, data from the 4-year monitoring period have a mean value of $\pm 75000 \mathrm{CFU} / 100 \mathrm{~m} \ell$, median of \pm 25 $000 \mathrm{CFU} / 100 \mathrm{~m} \ell$, and $98^{\text {th }}$ percentile of $\pm 400000 \mathrm{CFU} / 100 \mathrm{~m} \ell$. Note, however, that samples were not usually collected during rain events.

The second field survey covered a 2-week period during which daily grab samples were taken from Argyle SWD and from five locations on a $250 \mathrm{~m}$ section of Battery Beach around the drain outfall (see Fig. 2). Flow rates in the drain were also measured. Fig. 4 shows a time series of averaged beach E.coli counts together with recorded daily rainfall. E.coli counts fluctuated significantly from day to day with peak pollution levels usually not persisting for more than a day. This indicates that the decay timescale is about 1-day. One of the peaks evident in the beach data does not coincide with any rainfall but was also present in storm-water samples. Argyle SWD had a persistent dry weather flow (measured as $0.03 \mathrm{~m}^{3} / \mathrm{s}$ ) that

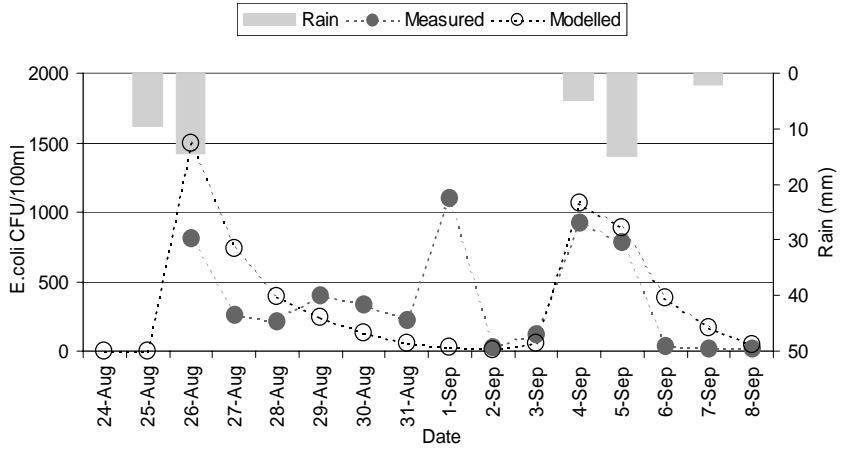

Figure 4

Battery Beach E.coli (CFU/100 me) and rainfall during a two week period 26/8/2002 - 8/9/2002

would have carried the high pollution load into the beach waters. The model predictions shown in Fig 4 are discussed below.

\section{Model set-up and calibration}

The Durban coastline was divided into 10 cells that incorporate the beaches shown in Fig. 2. The cells were assigned a length of $750 \mathrm{~m}$, and volume of $200000 \mathrm{~m}^{3}$. Catchment areas for each of the stormwater drains were measured from maps. Runoff coefficients were assumed to be $50 \%$.

The model parameters $T_{D}$ and $T_{A}$ were assumed constant across the model domain, with the advection time scale inversely proportional to the daily average wind speed:

$$
T_{A}=\beta L_{\text {cell }} / U_{\text {wind }}
$$
where:

$L_{\text {cell }}$ and $U_{\text {wind }}$ are cell length and wind speed respectively $\beta$ is a dimensionless coefficient with magnitude of order $10^{3}$

(Mardon, 2003). Wind directions relative to the coastline determine the advection direction.

Daily cell concentrations were simulated using the available 4-year historical record of wind and rainfall. The simulated time series, and statistics derived from it, could then be compared with data from the monitoring record.

\section{Model results}

The model parameter space was explored using simulation, and the range of values that gave outputs in reasonable agreement with the measurement record are summarised in Table 1. Values for event mean concentrations are shown relative to measured statistics for the storm-water drains i.e. the mean and $95^{\text {th }}$ percentile values. The $T_{\text {A }}$ values in Table 1 are based on average wind speeds (with $\beta \sim 500$ ). The model results were not sensitive to the dependence of $T_{A}$ on wind speed so that constant (average) values can be used, but directional information is still required.

\begin{tabular}{|c|c|c|c|}
\hline \multicolumn{4}{|c|}{ TABLE1 } \\
Typical model parameter values \\
\hline$T_{D}$ (days) & $T_{A}$ (days) & $C_{E M C} / C_{\text {mean }}$ & $C_{E M C} / C_{95}$ \\
\hline $1-2$ & $1-3$ & $0.4-1.0$ & $0.05-0.25$ \\
\hline
\end{tabular}




\begin{tabular}{|c|c|c|c|c|c|c|}
\hline \multicolumn{7}{|c|}{$\begin{array}{l}\text { TABLE2 } \\
\text { Measured and modelled water quality statistics: } \\
\text { average E.coli counts (CFU/100 ml) and percentage } \\
\text { exceedances of } 100 \& 2000 \text { CFU/100 me }\end{array}$} \\
\hline \multirow[t]{2}{*}{ Beach } & \multicolumn{3}{|c|}{ Measured } & \multicolumn{3}{|c|}{ Modelled } \\
\hline & Ave & $>100$ & $>2000$ & Ave & $>100$ & $>2000$ \\
\hline Vetches & 36 & $11 \%$ & $0 \%$ & 32 & $9 \%$ & $0 \%$ \\
\hline Addington & 73 & $9 \%$ & $1 \%$ & 53 & $15 \%$ & $0 \%$ \\
\hline South & 32 & $7 \%$ & $0 \%$ & 44 & $13 \%$ & $0 \%$ \\
\hline Wedge & 34 & $8 \%$ & $0 \%$ & 34 & $8 \%$ & $0 \%$ \\
\hline North & 37 & $13 \%$ & $0 \%$ & 35 & $10 \%$ & $0 \%$ \\
\hline Bay of Plenty & 53 & $17 \%$ & $0 \%$ & 70 & $21 \%$ & $0 \%$ \\
\hline Battery & 620 & $54 \%$ & $5 \%$ & 532 & $45 \%$ & $8 \%$ \\
\hline Country Club & 127 & $26 \%$ & $0 \%$ & 171 & $40 \%$ & $0 \%$ \\
\hline Laguna & 253 & $41 \%$ & $1 \%$ & 177 & $38 \%$ & $0 \%$ \\
\hline UmgeniS & 1291 & $67 \%$ & $17 \%$ & 1154 & $48 \%$ & $20 \%$ \\
\hline
\end{tabular}

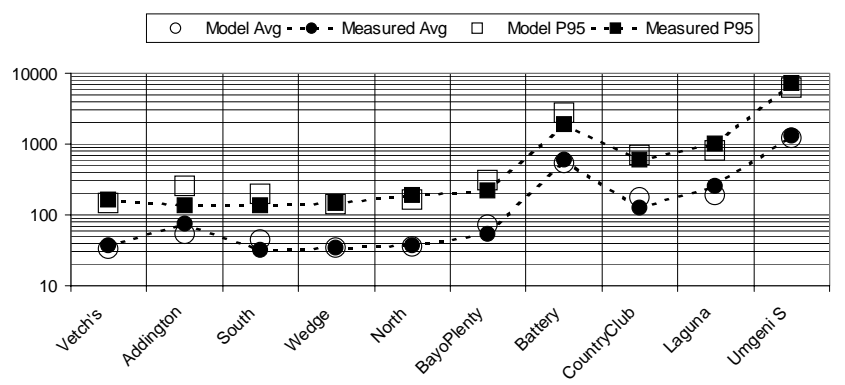

Figure 5

Measured and modelled beach E.coli statistics including average and $95^{\text {th }}$ percentile values

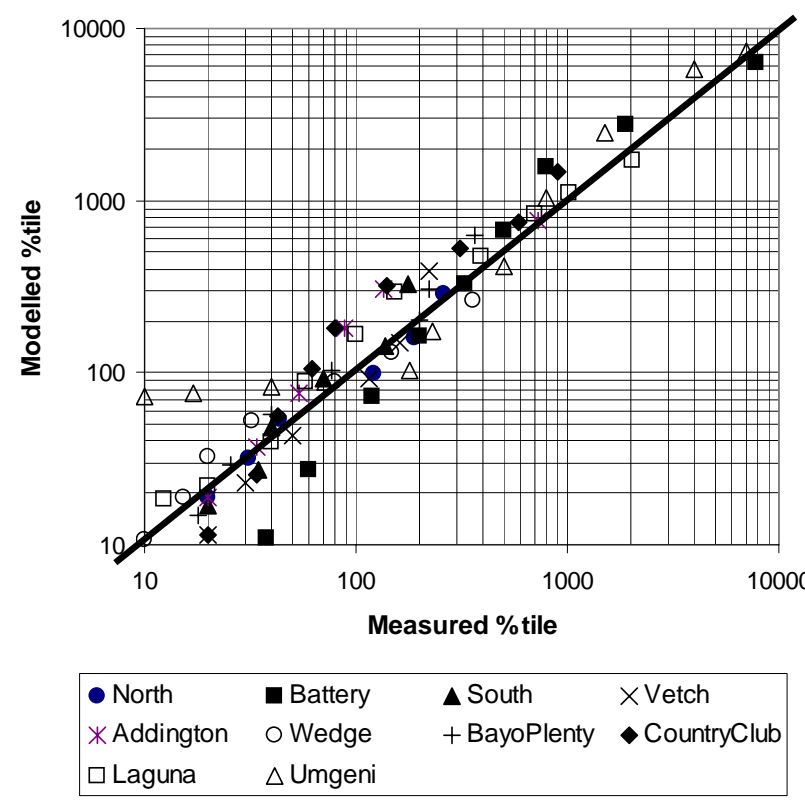

Figure 6

Scatter plot of measured and modelled E. coli percentiles
Table 2 and Figs. 5 and 6 give detailed statistical results from the simulations for comparison with measured values. The exceedance statistics in Table 2 are used in local water quality guidelines (DWAF, 1995). Figure 5 shows mean and $98^{\text {th }}$ percentile concentrations for the 10 beaches. Figure 6 is a scatter plot of 13 percentiles, from $1 \%$ to $99 \%$, for all the beaches. The correlation coefficient for the data in Fig. 6 is $0.97\left(\mathrm{R}^{2}=0.95\right)$. It is evident from the results shown that the model can accurately reproduce the measured statistics of beach pollution at the case study beaches.

The field study described above is the only one that has available data with sufficient temporal resolution for evaluating the model's performance in making real-time predictions of beach pollution levels. Simulation results for the 14-day field study period are included in Fig. 4. Generally the model performs satisfactorily, but since its input loadings are linked directly to rainfall events, it cannot reproduce the peak concentration that occurred during the dry period. The cause of the observed peak is not clear since the source of the dry period flow was not investigated. Mardon (2003) has shown that if the actual measured flow rates and pollution loadings for the Argyle drain are used as inputs to the model, it can closely mimic the observed beach pollution levels, including the dry period peak.

The model has been used to analyse a "what-if" scenario concerning the water quality problems of Battery Beach. This is the most polluted designated bathing beach in Durban, and often fails both local and international water quality guidelines (Mardon \& Stretch, 2004). The dominant source of the pollution is the Argyle storm-water drain (Fig. 2). Simulations were carried out to investigate by how much the Argyle pollution loadings need to be reduced in order to improve the water quality to acceptable levels. The results are shown in Table 3 - the model predicts that over $80 \%$ reduction in pollution loading is required in order to meet South African water quality guidelines, which are based on exceedance statistics. The simulation also indicates that nearby beaches, such as North and Bay-of-Plenty, would benefit from this improvement. This is significant because they are important to the local tourism industry.

\begin{tabular}{|l|c|}
\hline \multicolumn{2}{|c|}{ TABLE3 } \\
\begin{tabular}{|l|} 
Required reduction in pollution loadings for Argyle \\
SWD to meet South African Water Quality Guidelines
\end{tabular} \\
\hline SA WQ Guideline & Reduction \\
\hline $\begin{array}{l}\text { Less than 20\% to exceed 100 CFU/100 m } \ell \\
\text { Less than 5\% to exceed 2000 CFU/100 m } \ell\end{array}$ & $\begin{array}{l}>80 \% \\
>30 \%\end{array}$ \\
\hline
\end{tabular}

Mardon (2003) applied the model to further investigate treatment options for Argyle storm-water outflows. Simulations indicated that a constructed wetland (e.g. Kadelec \& Knight, 1996) might be used in this case, since it could readily provide the required $80 \%$ reduction in pathogenic pollution loading.

\section{Conclusions}

While there are a number of existing models for urban runoff water quality and for dispersion in the coastal zone, they are cumbersome to use for everyday management of beach use. A simplified model, with only two basic parameters and straightforward input requirements, has therefore been developed and tested using Durban as a case study site and E. coli as a water quality indicator. Good results have been achieved with the model shown to be capable of repro- 
ducing historical pollution data.

The application of the model as a "what-if” tool for management decisions has been illustrated by using it to investigate the pollution of Battery Beach. The model predicts that at least $80 \%$ reduction in the pollution loading from Argyle storm-water drain is needed to meet local water quality guidelines.

The proposed model is intended for real-time water quality predictions and seems capable of performing adequately in that respect. However, more detailed measurements that resolve the fluctuations in pollution over time scales of 1-day (or less) are required to fully evaluate its real-time performance.

The model proposed here has only been tested at a single case study site using pathogen indicators as state variables. It should be readily adaptable to other locations and alternative state variables, although data such as input loadings are likely to be very site-specific and would usually require fieldwork for estimation. Further testing and calibration is therefore required to fully assess the broader applicability of the model. A particular issue that requires further investigation concerns the input loadings associated with dry period flows. In its present form, the model does not yet address this issue in detail and is therefore not applicable to cases where these loadings contribute significantly to beach pollution.

\section{Acknowledgements}

The authors are grateful to Ms Siobhan Jackson of eThekwini Metro Water and Sanitation Services for providing water quality data. The South African Weather Service and CSIR provided wind, wave and rainfall data. Mr S Wesson and Mr A Brahmin carried out the fieldwork as students under the supervision of Prof D Stretch. The research was funded by a grant from the Innovation Fund (SA-ISIS project).

\section{References}

CHAMBERLIN C and MITCHELL R (1978) A decay model for enteric bacteria in natural waters. Water Pollut. Microbiol. Vol. 2, John Wiley \& Sons, New York. 325-348.

CHANG GC, PARRISH JH and SOEUR C (1990) The First Flush of Runoff and its Effects on Control Structure Design. Report by the Environmental and Conservation Services, Austin, Texas, USA. (www.cwp.org)

CHAO SY (1988) Wind-driven motion of estuarine plumes. J. Phys. Oceanogr. 18 (8) 1144-1166.

CHEN CT (1970) Introduction to Linear System Theory. Holt, Reinhart \& Winston, USA.
CHENG Z and MITSUYASU H (1992) Laboratory study on the surface drift current induced by wind and swell. J. Fluid Mech. Vol. 243 247-259.

CHOW VT, MAIDMENT DR and MAYS LW (1988) Applied Hydrology. McGraw-Hill.

COLEMAN TJ and SIMPSON DE (1996) Adaption and Calibration of an Urban Runoff Quality Model. WRC Report No 299/1/96.

COM (2002) Proposal for a Directive of the European Parliament and of the Council Concerning the Quality of Bathing Water. Commission of the European Communities, 2002/0254 (COD), Brussels, Nov. 24.

DWAF (1995) South African Water Quality Guidelines for Coastal Marine Waters. Vol. 2: Recreational Use. Department of Water Affairs and Forestry ( $1^{\text {st }}$ edn.).

EDWARDS, AWF (1984) Likelihood. CUP.

HAGER MC (2001) Evaluating First Flush. STORMWATER Vol 2 (6) Sept/Oct. (www.forester.net/sw.html)

JAZWINSKI AH (1970) Stochastic Processes and Filtering Theory. Academic Press. New York

HEANEY JP, HUBER WC, SHEIKH H, MEDINA MA, DOYLE JR, PELTZ WA and DARLING JE (1975) Urban Stormwater Management Modeling and Decision Making. US Environmental Protection Agency, EPA-670/2-75-022.

KADELEC RH and KNIGHT RL (1996) Treatment Wetlands. Lewis Publishers, New York.

MARDON DW and STRETCH DD (2002) The effects of wind speed, direction and duration on crosscurrents at the port of Durban entrance. In: Proc. HEFAT2002 - $1^{\text {st }}$ Int. Conf. on Heat Transfer, Fluid Mechanics \& Thermodynamics, Kruger Park, South Africa.

MARDON DW (2003) Coastal Water Quality. M.Sc.Eng. dissertation, University of Natal.

MARDON DW and STRETCH DD (2004) Comparative assessment of water quality at Durban beaches according to local and international guidelines. Water SA 30 (3) 317-324.

STANDARD METHODS (1992) Standard Methods for the Examination of Water and Waste Waters (18th edn.). Clesceri LS, Greenberg $\mathrm{AE}$ and Strussell RR (eds.), American Public Health Association.

US EPA (1985) Rates, Constants and Kinetic Formulations in Surface Water Quality Modelling ( $2^{\text {nd }}$ edn.), Environmental Research Laboratory, US Environmental Protection Agency, Athens, Georgia.

US EPA (1986) Ambient Water Quality Criteria for Bacteria, US Environmental Protection Agency, Washington, DC.

US EPA (1999) Review of Potential Modelling Tools and Approaches to Support the BEACH Program. US Environmental Protection Agency, Washington, DC.

WRIGHT A, KLOPPERS W and FRICKE A (1993) A hydrological investigation of the stormwater runoff from the Khayelitsha urban catchment in the False Bay area, South Western Cape. WRC Report No 323/1/93.

WU J (1974) Wind-induced drift currents. J. Fluid Mech. 68 49-70. 